\title{
Seleção de linhagens de Xanthomonas campestris para a produção de goma xantana
}

\section{Selection among strains of Xanthomonas campestris for xanthan gum production}

\author{
Márcia de Mello Luvielmo'; Claire Tondo Vendruscolo²; \\ Adilma Regina Pippa Scamparini ${ }^{3}$
}

\section{Resumo}

Pesquisas para a descoberta de novas cepas produtoras do biopolímero vêm despertando o interesse de inúmeros pesquisadores, que procuram por microrganismos com capacidade de produção de goma e qualidade superiores às existentes. $\mathrm{O}$ estudo em questão selecionou os patovares $X$. campestris $\mathrm{pv}$. manihotis 280-95, X. campestris pv. begoniae 1138-95 e X. campestris pv. dieffenbachiae 1429-00, como os de melhor desempenho, com uma produção de goma xantana de 10,8 g/L, 9,0 g/L e 8,5 $\mathrm{g} / \mathrm{L}$, respectivamente. Sendo a linhagem $280-95$ a de melhor desempenho em produção e qualidade. $\mathrm{O}$ estresse alcalino aplicado no processo de produção da goma xantana da X. campestris pv. manihotis $280-95$, aumentou em $40,76 \%$ a produção da goma, merecendo um estudo mais profundo, a fim de determinar as melhores condições para a aplicação desse processo.

Palavras-chave: Xanthomonas campestris. Seleção. Goma xantana. Estresse alcalino. Viscosidade. Otimização.

\begin{abstract}
Research on new strains biopolymers have raised the interest of many researchers who study microorganisms with gum production capacity and a higher quality than the existent ones. The present study selected patovars $X$. campestris pv. manihotis 280-95, X. campestris pv. begoniae 1138-95 and $X$. campestris pv. dieffenbachiae $1429-00$, as best performers, with xanthan gum producing 10,8 g. $\mathrm{L}^{-1}$, 9,0 g.L $\mathrm{L}^{-1}$ and 8,5 g.L. $\mathrm{L}^{-1}$ respectively, being strain $280-95$ the best in production and quality. The alkaline stress applied in the process of xanthan gum production of $X$. campestris pv. manihotis $280-95$ increased in $40,76 \%$, deserving more in depth studies to determine the best conditions for the application of the process.
\end{abstract}

Keywords: Xanthomonas campestris. Selection. Xanthan gum. Alkaline stress. Viscosity. Optimization.

\footnotetext{
1 Doutor em Ciência de Alimentos, Universidade Estadual de Campinas, Professor Adjunto do Departamento de Ciência de Alimentos, Universidade Federal de Pelotas. Email: luvielmo@ufpel.tche.br.

2 Docente do Departamento de Ciência de Alimentos, Universidade Federal de Pelotas. Email: claire@tche.ufpel.br.

3 Docente do Departamento de Ciência de Alimentos, Universidade Estadual de Campinas. Email: scamparini@uol.com.br.
} 


\section{Introdução}

Xanthomonas é um gênero da família da Pseudomonaceae. Com exceção da bactéria Xanthomonas maltophilia todos os outros microrganismos desse gênero são fitopatogênicos, (SUTHERLAND, 1993; SWINGS; VAUTERIN; KERSTERS, 1993). A Xanthomonas infecta uma extensa variedade de plantas incluindo alguns de interesse comercial como a alcachofra, o algodão, a ameixa, a berinjela, o brócolis, a couve, a couve-flor, a couve de Bruxelas, o maracujá, a mostarda, a nectarina, a pimenta, o pimentão, o rabanete, o repolho, o tomate, a alfafa, o pêssego e outras (NATIONAL COLLECTION OF PLANT PATHOGENIC BACTÉRIA - NCPPB, 2006).

As bactérias pertencentes ao gênero Xanthomonas podem produzir goma xantana, um polissacarídeo de enorme interesse para as indústrias de alimentos, farmacêuticas e de petróleo. A goma apresenta capacidade de formar soluções viscosas e géis hidrossolúveis que the fornecem propriedades reológicas únicas.

A maioria dos estudos informa uma dependência clara entre linhagens usadas, rendimento e propriedades da goma xantana. Assim, a seleção da linhagem precisa ser o primeiro passo para um processo específico de produção (LÓPEZ; MORENO; RAMOS-CORMENZANA, 2001; HASSLER; DOHERTY, 1990).

Atualmente, toda a goma xantana consumida no Brasil, provém de importações, porém o Brasil tem um grande potencial para a fabricação deste polímero em escala industrial, já que temos matériaprima básica para sua produção: açúcar e álcool do setor sucro-alcooleiro.

Esse estudo teve como objetivos selecionar linhagens de $X$. campestris em processo de fermentação normal, e testar o efeito do processo de estresse alcalino ao final do processo fermentativo, para avaliar a produção e a qualidade dos biopolímeros obtidos.

\section{Material e métodos}

\section{Microrganismos}

Foram utilizadas culturas liofilizadas das bactérias $X$. campestris pv. begoniae 1138-95, $X$. campestris pv. malvacearum $1779-02, X$. campestris pv. dieffenbachiae 1429-00, X. campestris pv. campestris $729-89, X$. campestris pv. vesicatoria 1460-99, X. campestris pv. manihotis 280-95 e $X$. campestris pv. campestris CA110 (NRRL B-1459) pertencentes à Coleção de Cultura da Seção de Bacteriologia Fitopatológica do Instituto Biológico de Campinas/SP-Brasil.

\section{Meios de cultura}

Foram utilizados os meios YM padrão (YeastMalt) sólido e líquido descritos por Haynes, Wickerham e Hesseltine (1955), o meio I segundo Souw e Demain (1979) e o meio nutriente conforme Pelczar, Reid e Chan (1981).

O meio YM padrão (Yeast-Malt) foi constituído por $(\mathrm{p} / \mathrm{v})$ : extrato de levedura $0,3 \%$, extrato de malte $0,3 \%$; peptona $0,5 \%$; glicose $1,0 \%$; e ágar (para meio sólido) $2,5 \%$.

O meio de fermentação (Meio MP-I), previamente testado foi constituído por (p/v): $\mathrm{MgSO}_{4} \cdot 7 \mathrm{H}_{2} \mathrm{O}$ $0,02 \%, \mathrm{KH}_{2} \mathrm{PO}_{4} 0,5 \%, \mathrm{H}_{3} \mathrm{BO}_{3} 0,0006 \%,\left(\mathrm{NH}_{4}\right)_{2} \mathrm{SO}_{4}$ $0,2 \%, \mathrm{FeCl}_{3} 0,00024 \%, \mathrm{CaCl}_{2} .2 \mathrm{H}_{2} \mathrm{O} 0,0002 \%, \mathrm{ZnSO}_{4}$ $0,0002 \%$, ácido cítrico $0,20 \%$ e sacarose $5 \%$.

$\mathrm{O} \mathrm{pH}$ do Meio MP-I foi ajustado para 7,0 com $\mathrm{HCl} 0,1 \mathrm{~N}$ e $\mathrm{NaOH} 0,1 \mathrm{~N}$.

Os meios foram esterilizados a $121^{\circ} \mathrm{C}$ por 20 $\min$. A sacarose foi esterilizada separadamente.

O meio nutriente foi constituído por $(\mathrm{p} / \mathrm{v})$ : extrato de carne $0,3 \%$, peptona $0,5 \%$ e $\mathrm{NaCl} 0,8 \%$. 
Procedimento de re-hidratação das culturas liofilizadas

As culturas estavam acondicionadas em ampolas de vidro, as quais foram quebradas em condições estéreis e colocadas no interior de tubos de ensaio estéreis com tampa rosqueável. Com pipeta de Pasteur foram adicionadas 6-8 gotas de meio nutriente às ampolas, e agitadas e incubadas a $28^{\circ} \mathrm{C}$ por 60 min. Transcorridos $60 \mathrm{~min}$, as suspensões foram transferidas para placas contendo meio YM padrão sólido e incubadas a $28^{\circ} \mathrm{C}$ por $48 \mathrm{~h}$ (INSTITUTO BIOLÓGICO, SECÇÃO DE BACTÉRIAS FITOPATOGÊNICAS - IBSBF, 2003).

As placas onde cresceram as bactérias oriundas das culturas liofilizadas foram chamadas de placa mãe. A partir desta placa colheu-se material de uma colônia isolada e esse material foi repassado para outra placa contendo meio YM padrão sólido. Esse procedimento foi repetido três vezes em duplicata (placa chamada de placa para produção) antes de utilizarmos cada um dos microrganismos para a produção do biopolímero.

\section{Preservação e manutenção dos microrganismos}

Para evitarpossíveis perdas na viabilidade celulare ter maior segurança na manutenção das características das bactérias, estas foram estocadas a $4^{\circ} \mathrm{C}$ em tubos de ensaio contendo meio YM ágar inclinado, e cobertas por óleo mineral. Quando necessário, foram reativadas, através de plaqueamento em meio YM padrão sólido e incubação a $28^{\circ} \mathrm{C}$ por $48 \mathrm{~h}$, e repassadas três vezes, antes de serem utilizadas para nova produção de polímero.

Segundo Cadmus et al. (1978) é de grande importância o controle da formação de colônias variantes, que são pequenas e não gomosas e acarretam diminuição na produção de goma.

\section{Produção do biopolímero}

Preparação do pré-inóculo e contagem de células viáveis

Em tubos de ensaio estéreis contendo $3 \mathrm{~mL}$ de meio YM padrão líquido estéril foram inoculadas nove alçadas padrão (alça de platina com 3,0 mm de diâmetro) da cultura bacteriana, crescida em placa de Petri (placa de produção) contendo meio YM padrão sólido. O material foi agitado e foram adicionados mais $3 \mathrm{~mL}$ de meio YM padrão líquido estéril. Esse procedimento foi padronizado, a fim de se obter um pré-inóculo contendo no mínimo 2,6 x $10^{9} \mathrm{UFC} / \mathrm{mL}$ (PAN; MOREIRA; VENDRUSCOLO, 2000).

As amostras de cada pré-inóculo foram submetidas a diluições decimais em série, transferindo-se $1 \mu \mathrm{L}$ de inóculo para $9 \mu \mathrm{L}$ de água sucessivamente até as diluições de $10^{-8}, 10^{-9}$ e $10^{-}$ ${ }^{10}$, transferindo-se $100 \mu \mathrm{L}$ de amostra diluída para a superfície de placas contendo meio YM-sólido. As colônias foram contadas após $48 \mathrm{~h}$ de incubação a $28^{\circ} \mathrm{C}$. Todos os testes de contagem foram feitos em duplicata. Os resultados foram expressos em Unidade Formadoras de Colônias por $\mathrm{mL}$ (UFC/ mL) (SILVA; JUNQUEIRA, 1995). Imediatamente após o preparo do pré-inóculo foi feito o inóculo.

\section{Inóculo}

Foram preparados cinco erlenmeyers de $125 \mathrm{~mL}$ ( $\mathrm{N}^{\circ}$ 4980, stopper $\mathrm{n}^{\circ}$ 05, Pyrex, USA), contendo 7 $\mathrm{mL}$ cada de meio YM padrão onde foi colocado 1 $\mathrm{mL}$ do pré-inóculo. Esse procedimento foi realizado para cada uma das culturas.

Os erlenmeyers foram colocados em um incubador agitador orbital (marca New Brunswick Scientific Co, modelo G27) e mantidos a uma temperatura de $28^{\circ} \mathrm{C}$ sob agitação de $180 \mathrm{rpm}$ por 24 horas (segundo o método de SOUZA; VENDRUSCOLO, 1999, modificado). 


\section{Fermentação}

Após 24h esse material foi transferido sob condições estéreis para um erlenmeyer de $250 \mathrm{~mL}$ $\left(\mathrm{N}^{\circ} 4980\right.$, stopper $\mathrm{n}^{\circ}$ 06, Pyrex, USA), contendo $43 \mathrm{~mL}$ de meio de fermentação (Meio MP-I), previamente testado. Os erlemeyers foram colocados em um incubador agitador orbital e mantidos a uma temperatura de $28^{\circ} \mathrm{C}$, sob a agitação de $200 \mathrm{rpm}$ por 72 horas (SOUZA; VENDRUSCOLO, 1999).

\section{Estresse alcalino}

Após as 72 horas de fermentação, os erlenmeyers foram levados para uma capela de fluxo laminar. Adicionou-se aos erlenmeyers hidróxido de sódio 2,0 $\mathrm{N}$ até atingir-se o $\mathrm{pH} 11$. O controle desse $\mathrm{pH}$ foi realizado através de pHmetro digital. Após o ajuste do $\mathrm{pH}$ os frascos retornaram ao incubador agitador orbital e foram mantidos por 1 hora. $\mathrm{O}$ tratamento de estresse alcalino foi testado apenas na bactéria que produziu a maior quantidade de goma xantana, a $X$. campestris pv. manihotis 280-95. Os experimentos foram realizados em triplicata.

\section{Separação do biopolímero}

O caldo fermentado foi centrifugado a 22.300 $\mathrm{x}$ g em centrífuga (marca Hitachi, modelo CR 21 ), a $20^{\circ} \mathrm{C}$ por $15 \mathrm{~min}$, para a precipitação da biomassa. Ao sobrenadante adicionou-se etanol $\left(92,8^{\circ} \mathrm{GL}\right)$ na proporção de $4: 1$, para precipitação dos biopolímeros. A suspensão foi agitada por 5 min, a goma recolhida com bastão de vidro e tela metálica. A goma obtida foi congelada e liofilizada. O material foi triturado e pesado (PAN; MOREIRA; VENDRUSCOLO, 2000, adaptado).

\section{Métodos analíticos}

\section{Quantidade de goma xantana produzida}

A goma liofilizada foi colocada em dessecador e pesada em balança analítica. A produção da goma xantana foi expressa em peso de goma (g) por volume de caldo fermentado (L).

\section{Qualidade da goma}

A qualidade da goma foi determinada por meio da viscosidade aparente. O comportamento reológico das amostras obtidas foi avaliado por meio de um reômetro rotativo da marca Haaker, modelo RS 150, sendo utilizado o sensor tipo copo, modelo DG 41. A determinação da viscosidade das amostras foi realizada a temperatura de $25^{\circ} \mathrm{C}$. As soluções aquosas foram preparadas na concentração de 1,0\% (p/v) em água destilada, solubilizadas por agitação durante duas horas, seguido de aquecimento a $60^{\circ} \mathrm{C}$ por 20 min (DIAZ, 2002; ZHANG XUEWU et al., 1996). Os parâmetros das análises reológicas foram: taxa de deformação aplicada entre $0,01 \mathrm{~s}^{-1}$ e $60 \mathrm{~s}^{-1}$, com fenda $5100 \mathrm{~mm}$ e tempo de $300 \mathrm{seg}$. Os ensaios foram realizados em triplicata.

\section{Composição química}

Utilizou-se o método comparativo de cromatografia de camada delgada (CCDC) desenvolvido por Moreira, Souza e Vendruscolo (1998), no qual as amostras foram hidrolisadas a $80^{\circ} \mathrm{C}$ por $16 \mathrm{~h}$ através da adição de $\mathrm{HCl} 2 \mathrm{~N}$, na proporção de 3:100 (p/v).

O produto da hidrólise foi analisado por cromatografia em camada delgada comparativa (CCDC), em placas de gel de sílica $\mathrm{F}_{254}$ (Merck), em cuba pré-equilibrada durante 10 minutos. Empregouse eluente composto por clorofórmio-metanol-ácido acético-água, na proporção de 40:40:10:10 (v/v/ v/v) (MOREIRA, SOUZA; VENDRUSCOLO, 1998). As amostras foram aplicadas com capilares padronizados. Para a revelação dos cromatogramas utilizou-se o reagente de detecção anisaldeídosulfúrico e aquecimento a $100^{\circ} \mathrm{C}$ durante $5 \mathrm{~min}$, seguindo-se visualização sob luz ultravioleta a $366 \mathrm{~nm}$ (WAGNER; BIADT; ZGAINSKI, 1984). A caracterização dos constituintes foi feita 
comparando-se com padrões de glicose, manose, fucose, ramnose e ácido glucurônico.

\section{Resultados e discussão}

\section{Número de células no inóculo}

Segundo Pan, Moreira e Vendruscolo (2000), o número de células iniciais no inóculo tem influência sobre a produção e a qualidade da goma produzida por $X$. campestris pv. pruni 06 . O estudo mostra que a produção de goma xantana assim como a viscosidade da solução obtida são maiores nos ensaios onde o número inicial de células está entre 2,6 x $10^{9} \mathrm{UFC} / \mathrm{mLe} 2,6 \times 10^{10} \mathrm{UFC} / \mathrm{mL}$. Entretanto Pan, Moreira e Vendruscolo (2000), testaram concentrações iniciais de inóculo de no máximo 2,6 x $10^{10} \mathrm{UFC} / \mathrm{mL}$. Nesse estudo foi verificado que os tratamentos com menores concentrações iniciais de células $\left(2,6 \times 10^{8}-1,3 \times 10^{9} \mathrm{UFC} / \mathrm{mL}\right)$ apresentaram menor produção e viscosidade aparente para os biopolímeros obtidos, além de grandes flutuações na curva de crescimento celular no intervalo de 96 horas de fermentação. Segundo Pan, Moreira e Vendruscolo (2000) e Baiocco (1997), partindo-se de um menor número de células, verifica-se uma maior multiplicação celular, porém, uma menor produção de goma xantana.

Já os tratamentos com maiores concentrações iniciais de células $\left(2,6 \times 10^{9}-2,6 \times 10^{10} \mathrm{UFC} / \mathrm{mL}\right)$ apresentaram maior produção, viscosidade aparente e estabilidade celular durante a fermentação (não havendo diferença significativa $\mathrm{p}<0,05$ para os resultados de produção neste intervalo de concentrações de células iniciais).

Os resultados da Tabela 1 mostram que as concentrações iniciais dos inóculos obtidos para os diferentes patovares estão entre $1,8 \times 10^{9}$ e $3,3 \times$ $10^{11} \mathrm{UFC} / \mathrm{mL}$.

Pan, Moreira e Vendruscolo (2000), Antunes (2000) e Souza (1999) sugerem que o número de células iniciais no inóculo seja superior a $10^{9} \mathrm{UFC} /$ $\mathrm{mL}$.
Tabela 1. Concentração do inóculo para cada um dos patovares testados

\begin{tabular}{ll}
\hline Identificação da Bactéria & UFC/mL no Inóculo \\
\hline $1429-99$ & $1 \times 10^{11}($ est.) \\
$729-00$ & $5 \times 10^{10}$ \\
$1138-95$ & $1,8 \times 10^{9}$ \\
CA110 & $2,5 \times 10^{9}$ \\
$1779-02$ & $3,3 \times 10^{11}$ \\
$1460-99$ & $5,4 \times 10^{10}$ \\
$280-95$ & $4,0 \times 10^{10}$ \\
\hline
\end{tabular}

\section{Produção de goma xantana}

Observou-se, na Figura 1, que para as condições utilizadas nesse estudo os patovares ou subespécies que apresentaram o melhor desempenho com relação à concentração de goma xantana obtida foram: $X$. campestris pv. manihotis 280-95, X. campestris pv. begoniae 1138-95 e $X$. campestris pv. dieffenbachiae 1429-99, com uma produção de goma xantana de 10,8 g.L $L^{-1}, 9,0$ g.L ${ }^{-1}$ e 8,5 g.L - $^{-1}$ respectivamente.

A partir desses resultados, escolheu-se a linhagem 280-95 para testar o efeito do estresse alcalino.

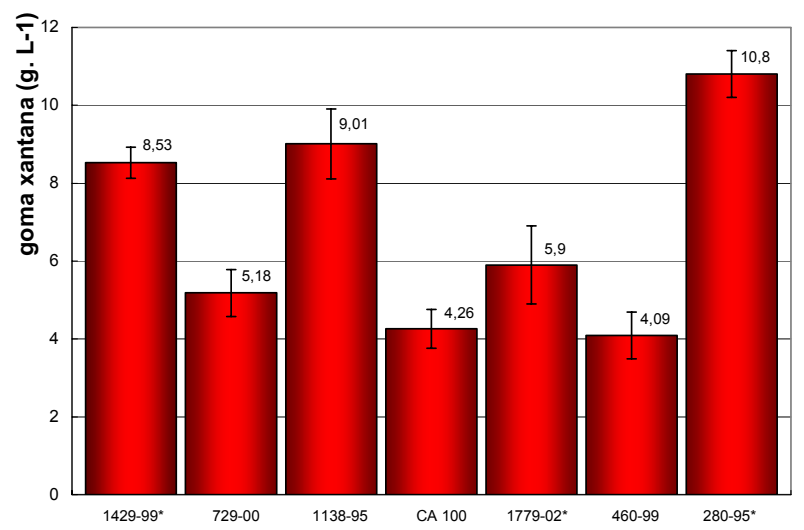

Figura 1. Produção de goma xantana $\left(\mathrm{g} . \mathrm{L}^{-1}\right)$ para as linhagens utilizadas na seleção. Nota: As amostras com * são as que apresentaram maiores valores de viscosidade aparente.

É bastante difícil comparar os resultados de produções de goma encontradas por outros autores, pois os resultados variam em função da bactéria utilizada, até mesmo entre linhagens de um mesmo gênero, espécie e subespécie e, também, em 
função da composição dos meios utilizados, e das condições de processo. Os autores Foresti (2003), Borges (2003), Moreira et al. (2001), Antunes et al. (2000), Nitschke e Thomas (1995), Galindo, Salcedo e Ramirez (1994) utilizaram condições muito semelhantes às condições utilizadas neste estudo.

Antunes et al. (2000) obtiveram resultados de produção de goma xantana entre 11,7 g.L $L^{-1}$ e 26,4 g.L $L^{-1}$, utilizando linhagens de $X$. campestris pv. pruni.

O estudo realizado por Moreira et al. (2001) apresentou condições muito semelhantes às utilizadas neste trabalho, com exceção do meio de produção de goma, pois nele foi utilizado o meio II. Moreira et al. (2001), realizaram uma seleção entre 18 diferentes linhagens de $X$. campestris pv pruni, os autores observaram uma grande variação na quantidade de goma xantana encontrada após 72 horas de fermentação, que foi de 2,3 g.L.- a 8,4 g.L $\mathrm{L}^{-1}$.

Galindo, Salcedo e Ramirez (1994) obtiveram rendimentos de 9,3 e 11,2 g. $\mathrm{L}^{-1}$ com as linhagens B 1459 e E2 (uma variante da 1459) de X. campestris pv. campestris respectivamente. Nitschke e Thomas (1995), utilizando linhagens selvagens de $X$. campestris pv. campestris, obtiveram produções de 10,6 g.L $\mathrm{L}^{-1}$ e 14,5 g.L $\mathrm{L}^{-1}$ para as linhagens C5 e Cv2C8 respectivamente.

Borges (2003) estudou 30 diferentes linhagens de $X$. campestris pv pruni, utilizando o meio II como meio de produção. Borges (2003) observou uma grande variação de produção de goma xantana para uma mesma linhagem, como no caso da linhagem 83 cuja produção variou de 0 a 9,2 g.L $\mathrm{L}^{-1}$.

Foresti (2003) determinou a produção de xantana (6,4 g.L - $\left.^{-1}\right)$ pela cepa padrão NRRL B-1459 de $X$. campestris pv. campestris, em condições idênticas a Borges (2003).

\section{Efeito do estresse alcalino na produção de goma} xantana

A concentração de goma xantana obtida com a utilização do X. campestris pv. manihotis 280-95 após o processo de estresse alcalino foi de 15,2 $\pm 0,92$ g.L

1 . Esse processo aumentou em $40,76 \%$ a produção da goma (Figura 2).

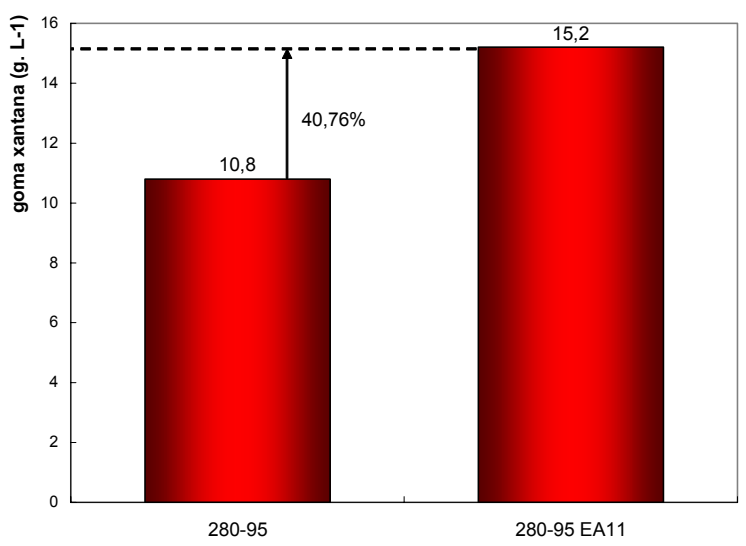

Figura 2. Produção de goma xantana $\left(\mathrm{g} \cdot \mathrm{L}^{-1}\right)$ para a linhagem $280-95$ sem o processo de estresse alcalino $(4,0$ x $\left.10^{10} \mathrm{UFC} / \mathrm{mL}\right)$ e com o processo de estresse alcalino em $\mathrm{pH} 11\left(5,5 \times 10^{11} \mathrm{UFC} / \mathrm{mL}\right)$ por 1 hora, utilizando o $\mathrm{NaOH}$.

Os autores acreditam na hipótese de que o processo de estresse alcalino tenha levado a mudanças estruturais na célula com subseqüente lise bacteriana, o que, de alguma forma, proporcionou uma maior produção ou precipitação do biopolímero.

$\mathrm{O}$ efeito do tratamento de estresse alcalino sob a produção de goma xantana merece um estudo mais profundo, a fim esclarecer o motivo do grande aumento no rendimento de goma com a aplicação desse tratamento.

\section{Viscosidade aparente das gomas produzidas}

Estudos mostram que as soluções de goma xantana são não-Newtonianas, apresentam um comportamento dependente do tempo e/ou da taxa de deformação e são fluidos altamente pseudoplásticos (PADILHA, 2003; CACIK; DONDO; MARQUÉS, 2001; BUENO; GARCIACRUZ, 2001; KATZBAUER, 1998).

Os dados obtidos nas avaliações de viscosidade aparente podem ser observados nas Figuras 3 e 4 . Todas 
as soluções aquosas a $1 \%$ de goma xantana obtidas de fermentações com as bactérias testadas, apresentaram comportamento de fluido pseudoplástico, como era esperado para as soluções aquosas de goma xantana. Esses resultados estão de acordo com os mostrados na literatura por Padilha (2003), Cacik, Dondo e Marqués (2001), Bueno e Garcia-Cruz (2001), Katzbauer (1998), Nitschke, Thomas e Knauss (1997), e Sandford e Baird (1983).

Na Figura 3, observa-se que a solução obtida a partir da goma xantana da linhagem 28095 apresentou maior viscosidade em taxas de deformação entre $0-60 \mathrm{~s}^{-1}$, com valor de viscosidade para taxa de deformação de $10,5 \mathrm{~s}^{-1}$ de $510 \mathrm{mPa}$.s.

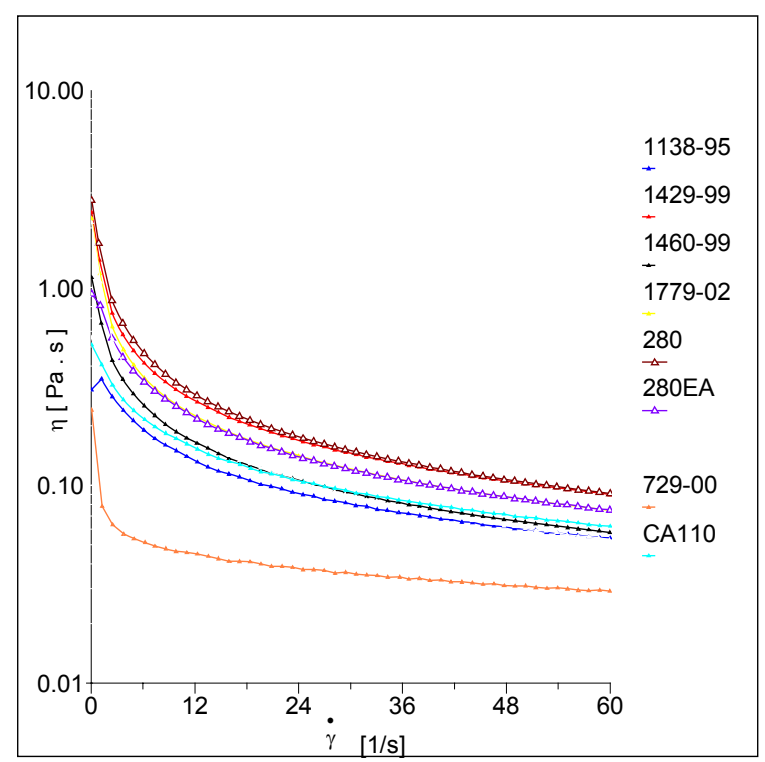

Figura 3. Viscosidade aparente (Pa.s) vs Taxa de deformação $\left(\mathrm{s}^{-1}\right)$, a $25^{\circ} \mathrm{C}$ das soluções de goma xantana $(1,0 \%$ $\mathrm{p} / \mathrm{v})$, produzidas pelas diferentes linhagens.

Além da goma produzida pela bactéria 280-95, as gomas produzidas pelas bactérias 1429-99 e 1779-02 também apresentaram bom desempenho no momento de taxa de deformação zero.

Observa-se, na Figura 4, que a solução obtida a partir da goma xantana da linhagem 280-95 sem estressealcalino apresentou $510 \mathrm{mPa}$.s de viscosidade aparente, a mesma linhagem após estresse alcalino apresentou $400 \mathrm{mPa}$.s para uma taxa de deformação de $10,5 \mathrm{~s}^{-1}$. O estresse alcalino diminuiu a qualidade da goma obtida pela linhagem 280-95, entretanto observou-se uma goma com característica mais elástica do que viscosa, sugerindo um estudo de viscoelasticidade.

Apesar da diminuição da viscosidade aparente para a linhagem 280-95 submetida ao estresse alcalino, essa ainda apresenta uma viscosidade aparente superior às encontradas para as linhagens 1460-99, CA 110, 1138-95 e 729-00 não submetidas ao tratamento de estresse alcalino, em uma taxa de deformação de $10,5 \mathrm{~s}^{-1}$.

Em taxas de deformação entre $0-60 \mathrm{~s}^{-1}$ as amostras 280-95, 1429-99, 1779-02 e 280-95 EA são as de maior viscosidade (Figura 3).

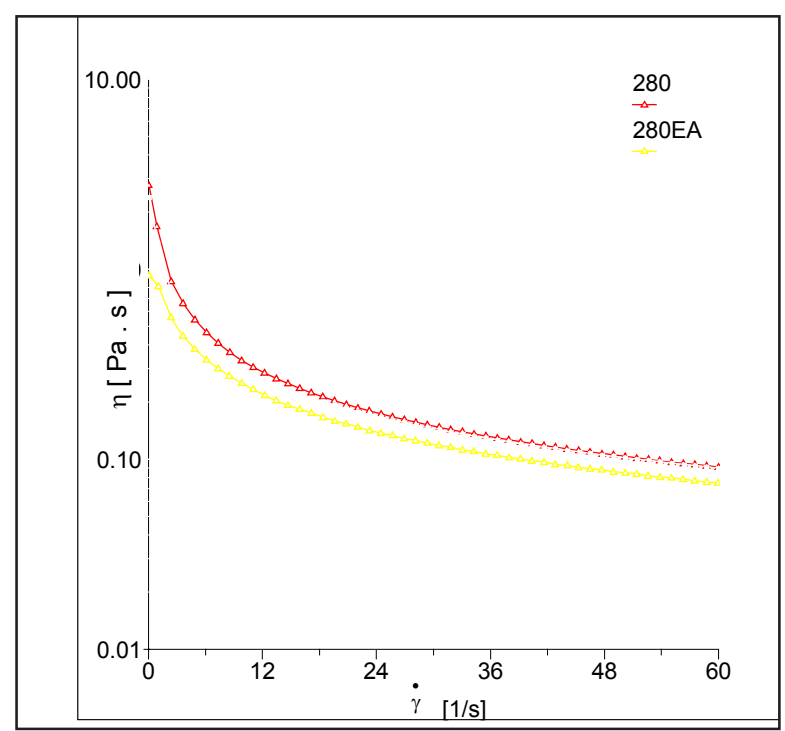

Figura 4. Viscosidade aparente (Pa.s) vs Taxa de deformação $\left(\mathrm{s}^{-1}\right)$, a $25^{\circ} \mathrm{C}$ das soluções de goma xantana $(1,0 \%$ p/v), amostras: 280-95 e 280-95 EA11.

No estudo realizado por Rottava (2005), o valor de viscosidade aparente encontrado para as gomas obtidas a partir do X. campestris pv. manihotis 1182 , $X$. campestris pv. campestris $607, X$. campestris pv. campestris $1078, X$. campestris pv. campestris 254 , X. campestris pv. arracaciae 1198 e X. campestris pv. campestris 729 foram respectivamente 360 mPa.s, 220 mPa.s, $230 \mathrm{mPa} . \mathrm{s}, 66 \mathrm{mPa} . \mathrm{s}, 37 \mathrm{mPa}$. $\mathrm{s}$ e $161 \mathrm{mPa} . \mathrm{s}$, para taxa de deformação de $10,5 \mathrm{~s}^{-1}$. 
As condições da análise reológica foram diferentes, e foi utilizada no estudo de Rottava (2005) uma solução aquosa três vezes mais concentrada do que a utilizada em nosso estudo, viscosímetro Brookfield, modelo LVDV III+, spindle 18 a $25^{\circ} \mathrm{C}$.

Borges (2003) apresentou em seu estudo a caracterização de 30 cepas de $X$. campestris pv pruni, utilizando condições para a avaliação da viscosidade semelhantes às utilizadas neste estudo, com exceção da concentração das soluções, que foi de 3\% (p/p). Apesar de utilizar o mesmo modelo de reômetro (HAAKE, RS150), foi utilizado o sistema placaplaca com sensor PP35Ti. Encontrou para uma taxa de deformação de $10 \mathrm{~s}^{-1}$ valores de viscosidade entre $12.700 \mathrm{mPa}$.s e $1.370 \mathrm{mPa}$.s. Para uma amostra de xantana comercial testada, encontrou $3.400 \mathrm{mPa} . \mathrm{s}$.

Foresti (2003) obteve uma viscosidade aparente da solução aquosa de goma xantana $(3 \% \mathrm{p} / \mathrm{p})$ de $2.700 \mathrm{mPa} . \mathrm{s}$ numa taxa de deformação de $10 \mathrm{~s}^{-1}$ para a xantana sintetizada pela cepa padrão NRRL B-1459 de $X$. campestris pv. campestris.

Nitschkee Thomas (1995), numa taxadedeformação de $12,5 \mathrm{~s}^{-1}$, relataram que as soluções aquosas a $0,5 \%$ (p/p) dos polímeros sintetizados por cepas selvagens de $X$. campestris, variaram de $200 \mathrm{mPa}$.s para a cepa Cv2C8, até $641 \mathrm{mPa}$.s para a cepa C7.

Souza e Vendruscolo (1999), ao determinar a viscosidade aparente das soluções aquosas a $3 \%$ de xantanas produzidas por $X$. campestris pv. pruni cepas 24 e 58, analisadas em reômetro HAAKE CV 20, obtiveram aproximadamente $5.000 \mathrm{mPa}$.s e 300 $\mathrm{mPa}$.s respectivamente, numa taxa de deformação de $10 \mathrm{~s}^{-1}$.

A goma xantana produzida pelo $X$. campestris pv. manihotis 280-95 apresentou as maiores viscosidades na faixa de taxa de deformação testada $\left(0-60 \mathrm{~s}^{-1}\right)$, atingindo viscosidade de $510 \mathrm{mPa} . \mathrm{s}$ para taxa de deformação de $10,5 \mathrm{~s}^{-1}$. Esse valor é inferior ao esperado para a xantana comercial, porém deve-se ressaltar que as amostras em questão não foram purificadas, o que prejudica seu desempenho reológico.
$\mathrm{Na}$ literatura, não foi encontrado estudo exatamente com as mesmas condições de processo e de análise reológica em que a goma xantana foi testada. Porém os relatos fornecem uma orientação quanto à grandeza esperada para goma xantana de boa qualidade e um produto comercial.

Industrialmente, existem muitos tipos de xantana com propriedades adequadas para cada tipo de aplicação. Geralmentel a xantana tipicamente utilizada em alimentos apresenta uma viscosidade de $1400 \mathrm{mPa}$.s (solução de 1\%, com adição de 1\% de $\mathrm{KCl}, 60 \mathrm{rpm}, 25^{\circ} \mathrm{C}$, viscosímetro Brookfield LVF, spindle 3), já a xantana utilizada para outros fins industriais apresenta viscosidade de $850 \mathrm{mPa}$. s $\left(60 \mathrm{rpm}\right.$ em $\left.11 \mathrm{~s}^{-1}\right)$ (CPKELCO, 2001; BRAUN; ROSEN, 2000).

\section{Análise de composição química}

Os biopolímeros obtidos foram analisados por CCDC para a identificação de monossacarídeos e ácidos constituintes. As amostras de gomas analisadas apresentaram perfis cromatográficos semelhantes (Figura 5-II). Na sua composição foram identificados os ácidos glucurônico com Rfde 0,30 , os monossacarídeos glicose e manose com $\mathrm{Rfde} 0,54$ e 0,56 respectivamente e sugere-se a presença de ramnose com valor de $\mathrm{Rf}$ 0,70, necessitando a aplicação de outras técnicas cromatográficas como co-cromatografia e CCDA-bidimensional para uma confirmação (OLIVEIRA et al., 2000; SOUZA, 1999).

A presença da ramnose pode ser uma característica desejável, pois, em geral, os polímeros nos quais este monossacarídeo está presente possuem capacidade de formar géis verdadeiros, quando em suspensão aquosa (KANG; MCNEELY, 1977). A xantana comercial, em solução aquosa, não tem capacidade de formação de gel, mesmo em altas concentrações. Por isso, a importância de ramnose quando se deseja encontrar biopolímeros que possam ser usados como estruturantes ou gelificantes. No entanto, os biopolímeros que formam géis em altas concentrações mudam seu comportamento 
reológico quando em baixas concentrações, não formando géis. Isso pode ser considerado como um aspecto positivo, pois amplia a utilização destes, podendo ser utilizado como gelificante, espessante ou estabilizante (SANDERSON, 1990; SOUW; DEMAIN, 1979).

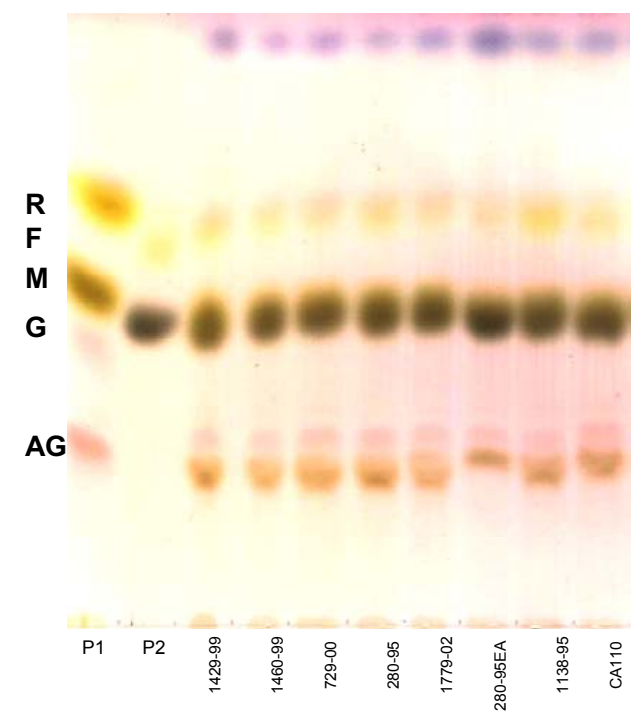

Figura 5. Cromatografia de camada delgada. Padrões: $\left(\mathrm{P}_{1}\right)$ Ácido Glucurônico (AG, Rf 0,30), Manose (M, Rf $0,56)$ e Ramnose (R, Rf 0,70); $\left(\mathrm{P}_{2}\right)$ Glicose (G, Rf 0,54) e Fucose (F, Rf 0,65). Eluido com clorofórmio-MetanolÁcido Acético-Água (40:40:10:10 v/v/v/v).

As diferenças na estrutura dos biopolímeros tendem ser principalmente devido a mudanças nas concentrações de piruvato e acetato, mas variações na composição de carboidratos também podem ocorrer. Em muitos casos, a proporção entre monossacarídeos é mantida (1:1), mas pequenas variações podem ocorrer entre diferentes espécies (SUTHERLAND, 1981) e em mutantes. HEYRAND et al. (1998) obtiveram um polímero de $X$. campestris pv. campestris 8396 , desprovido de ácido glucurônico, e nele a glicose e a manose estão em uma razão molar de 2:1. A presença de outros monossacarídeos tais como galactose e ramnose também têm sido relatada.

\section{Conclusão}

Para as condições utilizadas nesse estudo, as linhagens que apresentaram o melhor desempenho com relação à produção e qualidade de goma xantana obtida foram: $X$. campestris pv. manihotis 280-95, X. campestris pv. begoniae 1138-95 e $X$. campestris pv. dieffenbachiae 1429-00, com uma produção de goma xantana de 10,8 g.L - $^{-1}, 9,0$ g.L.- e 8,5 g. $\mathrm{L}^{-1}$ respectivamente.

A goma xantana produzida por $X$. campestris pv. manihotis 280-95 foi a que apresentou maior produção (g.L $\left.\mathrm{L}^{-1}\right)$ e também a maior viscosidade na faixa de taxa de deformação testada $\left(0-60 \mathrm{~s}^{-1}\right)$.

$\mathrm{O}$ rendimento fermentativo com $X$. campestris pv. manihotis 280-95 após o processo de estresse alcalino aumentou em 40,76\%, merecendo um estudo mais profundo acerca do efeito do estresse alcalino sob a produção de goma xantana e quais as melhores condições para esse processo.

\section{Referências}

ANTUNES, A. E. C. Produção, viscosidade e composição de xantana por Xanthomonas campestris pv. pruni em meios convencionais e alternativos. 2000. Dissertação. (Mestrado em Ciências e Tecnologia Agroindustrial) - Universidade Federal de Pelotas, Pelotas.

ANTUNES, A. E. C.; MOREIRA, A. S.; VENDRUSCOLO, J. L. S.; VENDRUSCOLO, C. T. Viscosidade aparente de biopolímeros produzidos por diversas cepas de Xanthomonas campestris pv. pruni. Ciência e Engenharia, Uberlândia, v. 9, n. 1, p. 83-87, 2000.

BAIOCCO, L. M. Estudo de parâmetros para a produção de inóculos liofilizados de $X$. campestris pv. manihotis. 1997. Tese. (Doutorado em Engenharia de Alimentos) - Universidade Estadual de Campinas, Campinas.

BORGES, C. D. Caracterização da goma xantana em função das cepas de $X$. campestris pv. pruni e das condições operacionais. 2003. Dissertação. (Mestrado em Ciências e Tecnologia Agroindustrial) - Universidade Federal de Pelotas, Pelotas. 
BRAUN, D. B.; ROSEN, M. R. Rheology modifiers handbook practical use and application. Norwich: New York, 2000.

BUENO, S. M.; GARCIA-CRUZ, C. H. The influence of fermentation time and the presence of salts in the rheology of the fermentation broth of a polysaccharide-producing bacteria free of soil. Journal of Food Engineering, Essex, v. 50, n. 1, p. 41-46, 2001.

CACIK, F.; DONDO, R. G.; MARQUÉS, D. Optimal control of a batch bioreactor for the production of xanthan gum. Computers and Chemical Engineering, New York, v. 25, n. 2-3, p. 409-418, 2001.

CADMUS, M. C.; KNUTSON, K. A.; LAGOTA, A. A.; PITTSLEY, J. E.; BURTON, K. A. Synthetic media for production of quality xanthan gum in 20 liter fermentors. Biotechnology and Bioengineering, New York, v. 20, p. 1003-1014, 1978.

CP KELCO Global leader in hydrocolloids. Xanthan gum book, CPKelco. Asp: 8. Ed., 28 p, 2001.

DIAZ, P. S. Influência de parâmetros físicos e químicos e da adição de íons no comportamento reológico de gomas xantana. 2002. Dissertação. (Mestrado em Ciências e Tecnologia Agroindustrial) - Universidade Federal de Pelotas, Pelotas.

FORESTI, A. P. Produção e qualidade reológica da xantana sintetizada por diferentes cepas de Xanthomonas em meios modificados. 2003. Dissertação. (Mestrado em Agronomia) - Universidade Federal de Pelotas, Pelotas.

GALINDO, E.; SALCEDO, G.; RAMIREZ, M. A. Preservation of $X$. campestris on agar slopes: effects on xanthan production. Applied microbiology and biotechnology, Berlin, v. 40, n. 4, p. 634-637, 1994.

HASSLER, R.A.; DOHERTY,D.H.Título. Biotechnology Process, Local, v. 6, n., p. 182-187, 1990.

HAYNES, W. C.; WICKERHAM, L. J.; HESSELTINE, C. W. Maintenance of cultures of industrially important microorganisms. Applied Microbiology, Washington, v. 3, n. 6, p. 361-368, 1955.

INSTITUTO BIOLÓGICO, SECÇÃO DE BACTÉRIAS FITOPATOGÊNICAS - IBSBF. Coleção de Cultura da Seção de Bacteriologia Fitopatológica do Instituto Biológico de Campinas/SP-Brasil. Campinas: IBSBF, 2003.

KANG, K. S.; McNEELY, W. PS-7. A new bacterial heteropolysaccharide. In: SANDFORD, P. A.; LASKIN, A. (Ed.) Extracellular Microbial Polysaccharide. Washington: Americam Chemical Society, 1977. p. 220230 .
KATZBAUER, B. Properties and applications of xanthan gum. Polymer Degradation and Stability, Essex, v. 59, n. 1, p. 81-84, 1998.

LÓPEZ, M. J.;MORENO, J.; RAMOS-CORMENZANA, A. X. campestris strain selection for xanthan production from olive mill wastewaters. Water research, New York, v. 35, n. 7, p. 1828-1830, 2001.

MOREIRA, A. S.; SOUZA, A. da S.; VENDRUSCOLO, C.T. Determinação da composição de biopolímero por cromatografia em camada delgada: Metodologia. Revista Brasileira de Agrociência, Pelotas, v. 3, n. 4, p. 222-224, 1998.

MOREIRA, A. S.; VENDRUSCOLO, J. L. S.; GILTURNES, C.; VENDRUSCOLO, C.T. Screening among 18 novel strains of $X$. campestris pv. pruni. Food Hydrocolloids, Oxford, v. 15, n.4-6, p. 469-474, 2001.

NATIONAL COLLECTION OF PLANT PATHOGENIC BACTÉRIA - NCPPB. Título Artigo. Disponível em: <www.ncppb.com>. Acesso em: dia mês 2006.

NITSCHKE, M.; THOMAS, R. W. S. P. Xanthan gum production by wild-type isolates of $X$. campestris. World Journal of Microbiology e Biotechnology, Oxford, v. 11, n. 5, p. 502-504, 1995.

NITSCHKE, M.; THOMAS, R. W. S. P. KNAUSS, C. Xanthan production by $X$. campestris in a whey-based medium. Revista de Microbiologia, São Paulo, v. 28, n. 1, p. 148-151, 1997.

OLIVEIRA, L. H. S.; DIAS, F. G.; DUARTE, I. C. S.; OLIVA-NETO, P.; CRUZ, R.; MOREIRA, A. S.; VENDRUSCOLO, C. T. Isolamento e caracterização de bactérias produtoras de goma xantana. Revista Cientifica Plural, Assis, v. 1, n. 1, p. 115-120, 2000.

PADILHA, F. F. Produção de biopolímeros sintetizados por microorganismos. 2003. Tese. (Doutorado em Engenharia de Alimentos) - Universidade Estadual de Campinas, Campinas.

PAN, A.; MOREIRA, A. S.; VENDRUSCOLO, C. T. Efeito da concentração inicial do inóculo no crescimento celular e qualidade de biopolímeros de $X$. campestris pv. pruni CEPA 06. Revista Brasileira de Agrociência, Pelotas, v. 6, n. 3, p. 273-277, 2000.

PELCZAR, M. J.; REID, R.; CHAN, E. C. S. Microbiologia. São Paulo: Mc Graw-Hill do Brasil, 1981. v. 2

ROTTAVA, I. Seleção de linhagens de Xanthomonas sp para produção de goma xantana. 2005. Dissertação (Mestrado em Engenharia de Alimentos) - Departamento de Ciências Agrárias da Universidade Regional Integrada do Alto Uruguai e das Missões, Erechim. 
SANDERSON, G. R. Gellan gum. Applied Science, New York, v. 479, n. 2, p. 201-232, 1990.

SANDFORD, P. A.; BAIRD, J. Industrial utilization of polysaccharides. In: ASPINALL, S. O. The polysaccharide. New York: Academic Press, 1983. v. 2, p. 412-490.

SILVA, N.; JUNQUEIRA, V. C. A. Contagem Total de microrganismo aeróbicos mesófilos/psicrotróficos e de bolores leveduras em placas. In: AUTOR. Métodos de análise microbiológica de alimentos. Campinas: ITAL, 1995. p. 21-29. (Manual Técnico, n. 14).

SOUW, P.; DEMAIN, A. L. Nutricional studies on xanthan production by $X$. campestris NRRL B-1459. Applied and Environmental Microbiology, Washington, v. 37, n. 6, p. 1186-1192, 1979.

SOUZA, A. S. Produção e caracterização dos biopolímeros sintetizados por $X$. campestris pv. pruni cepas 24 e 58. 1999. Dissertação. (Mestrado em Ciências e Tecnologia Agroindustrial) - Universidade Federal de Pelotas, Pelotas.
SOUZA, A S.; VENDRUSCULO, C. T. Produção e caracterização dos biopolímeros sintetizados por $X$. campestris pv pruni CEPAS 24 e 28. Ciência e Engenharia, Uberlandia, v. 8, n. 2, p. 115-123, 1999.

SUTHERLAND, I. W. Xanthomonas polysaccharides improved methods for their comparison. Carbohydrates and Polymer, Shannon, v. 1, n. 2, p. 107-115, 1981.

SUTHERLAND, I. W. Xanthan. In: SWINGS, J. G.; CIVEROLO, E. L. Xanthomonas. London: Chapman \& Hall, 1993. p. 363-388.

SWINGS, J. G.; VAUTERIN, L.; KERSTERS, K. The bacterium Xanthomonas. In: SWINGS, J.G.; CIVEROLO, E. L. Xanthomonas. London: Chapman \& Hall, 1993. p. 121-146.

WAGNER, H.; BIADT, S. ZGAINSKI, G. M. Plant drug analysis. New York: Springer-Verlag, 1984.

ZHANG XUEWU; LIU XIN; GU DEXIANG; ZHOU WEI; XIE TONG; MO YONGHONG. Rheological models for xanthan gum. Journal of Food Engineering, Essex, v. 27, n. 2, p. 203-209, 1996. 
